\section{A Simplified Pyruvic Acid Analysis Suitable for Onion Breeding Programs}

\author{
Kil Sun Yoo ${ }^{1}$, Leonard M. Pike ${ }^{2}$, and Brian K. Hamilton ${ }^{3}$ \\ Vegetable Improvement Center, Department of Horticultural Sciences, Texas \\ A\&M University, College Station, TX 77843
}

Onion pungency is estimated by analyzing enzymatically produced pyruvic acid (Schwimmer and Weston, 1961). This acid is produced by alliinase hydrolysis of a group of flavor-precursor $S$-alk(en)yl-L-cystein sulfoxides in onion tissues when they are mechanically chopped or macerated. Many sulfurvolatiles and ammonia also are produced during this reaction. There is a high correlation between enzymatically produced pyruvic acid and pungency perception (Schwimmer and Weston, 1961; Wall and Corgan, 1992). Thus, pyruvic acid concentration is suggested as a mildness selection criterion in onion breeding (Wall and Corgan, 1992).

Large-scale screening of onion bulbs for pungency requires a fast and cost-efficient method. The original procedure by Schwimmer and Weston (1961) is time-consuming because of extraction difficulties and juice dilution. A rapid method for collecting the onion extract using a press significantly reduced analysis time (Randle and Bussard, 1993). In the onion breeding program at Texas $A \& M$ Univ., we routinely screen $\approx 1000$ onion bulbs per year for mildness. Weighing onion tissues and blending with a fixed volume of water is slow, while filtration and additional dilution steps are cumbersome and require much glassware.

We simplified the original method of Schwimmer and Weston (1961) to shorten sample preparation and analysis time by 1) blending onion tissue without the addition of water to eliminate the weighing step needed to obtain 5-fold diluted juice, 2) filtering the blended puree into disposable Styrofoam cups, and 3) analyzing pyruvic acid using undiluted juice. This paper details the method and compares its accuracy with the original method using diluted juice.

Three or five onion bulbs from three cultivars (total 18 bulbs), out of storage or fresh harvest, were used in this study. The onion bulbs were cut longitudinally into two pieces. One-half was immediately chopped into pieces $\approx 2 \mathrm{~cm}$ square and homogenized without water for $1 \mathrm{~min}$ in an Osterizer (Oster, Milwaukee) blender at speed "mix." The other half was wrapped in a plastic bag, then cooked in a

Received for publication 10 Nov. 1994. Accepted for publication 2 May 1995. The cost of publishing this paper was defrayed in part by the payment of page charges. Under postal regulations, this paper therefore must be hereby marked advertisement solely to indicate this fact.

${ }^{1}$ Research Assistant Professor.

${ }^{2}$ Professor.

${ }^{3}$ Graduate Research Assistant. microwave oven for $3 \mathrm{~min}$ and blended to obtain the background pyruvic acid sample. The puree was poured into a filter paper (P8; Fisher Scientific, Pittsburgh) and placed in a $180-\mathrm{ml}$ Styrofoam cup and allowed to filter. After $\approx 30 \mathrm{~min}$, the vials were capped and stored at $-20 \mathrm{C}$ until analyzed.

A $100-\mu l$ homogenate was mixed with $3 \mathrm{ml}$ 2,4 dinitrophenylhydrazine (DNPH) (two volumes of $0.0125 \% \mathrm{DNPH}$ in $2 \mathrm{~N} \mathrm{HCl}$ mixed with one volume of water) and heated for 10 $\mathrm{min}$ at $40 \mathrm{C}$. Then $8 \mathrm{ml} 0.6 \mathrm{~N} \mathrm{NaOH}$ was added and color intensity was immediately measured at $420 \mathrm{~nm}$. A set of $0,1,2,4,6,8$, and 10 $\mu \mathrm{mol} \cdot \mathrm{ml}^{-1}$ sodium pyruvate standards was analyzed with unknowns. For comparison, the same juices were diluted 100-fold and analyzed as described by Schwimmer and Weston (1961). The pyruvic acid concentrations obtained by the two methods were compared by regression analysis using the SAS general linear model.

Pyruvic acid concentrations measured with undiluted homogenate and 100-fold diluted homogenate were positively correlated (Fig. 1). The undiluted homogenate method gave an average of $15 \%$ more pyruvic acid than the dilution method. This difference may be due to greater sample losses during dilution involvat $P<0.01$. ing three transfers of each sample, compared to direct analysis of the undiluted homogenate method involving only one transfer. However, the difference was minor and both methods were equally consistent and reliable. In a breeding program dealing with many samples, background pyruvate analysis can be omitted, as the concentration is generally low $(<0.5$ $\mu \mathrm{mol} \cdot \mathrm{ml}^{-1}$ ) and fairly consistent within a cultivar. The elimination of background samples also was suggested by Schwimmer and Weston (1961).

The new method using undiluted homogenate reduced dish washing significantly by use of disposable Styrofoam cups and plastic vials for juice extraction and required one-third the number of test tubes for analysis. The new method was well suited to our program where many samples are analyzed. Two technicians routinely collect 200 filtered homogenates with five blenders or analyze 300 frozen samples per day. Randle and Bussard (1993) shortened the pyruvic acid analysis time by streamlining the juice collection procedure; our method reduced the extraction and analysis time even further so that mass screening of onion populations for pungency is practical.

\section{Literature Cited}

Randle, W.M. and M.L. Bussard. 1993. Streamlining onion pungency analysis. HortScience 28:60.

Schwimmer, S. and W.J. Weston. 1961. Enzymatic development of pyruvic acid in onion as a measure of pungency. J. Agr. Food Chem. 9:301304.

Wall, M.M. and J.N. Corgan. 1992. Relationship between pyruvate analysis and flavor perception for onion pungency determination. HortScience 27:1029-1030.

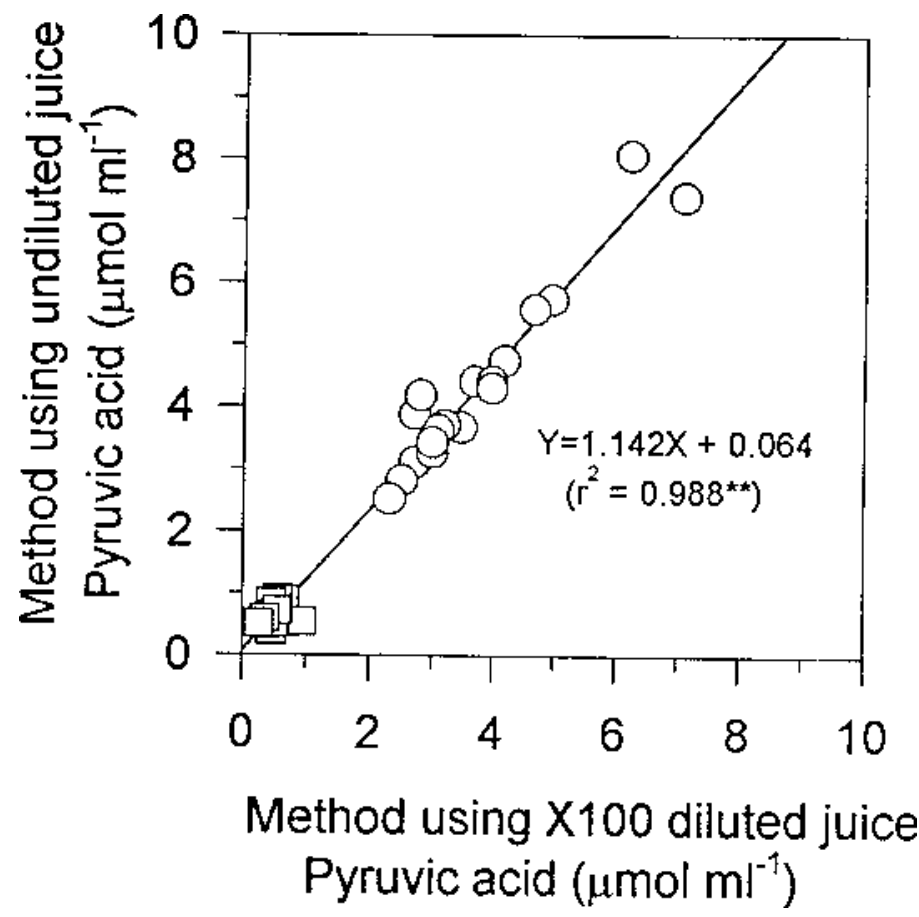

Fig. 1. Relationship between two pyruvic acid analysis methods using 100 -fold diluted juices and undiluted homogenates. Data points are $(\bigcirc)$ total and $(\square)$ background pyruvic acid concentrations. ${ }^{* *}$ Significant 